\title{
Perancangan bilah tipe taperless pada kincir angin: studi kasus di PT. Lentera Bumi Nusantara Tasikmalaya
}

\section{Design of taperless type blades on wind turbines: case studies at PT. Lentera Bumi Nusantara Tasikmalaya}

\section{N.H. Sari , W.G. Laksmana}

Jurusan Teknik Mesin, Fakultas Teknik, Universitas Mataram, Jl. Majapahit No. 62, Mataram, NTB, 83125, Indonesia. HP. 082235458894

*Email: n.herlinasari@unram.ac.id

\begin{tabular}{|c|c|}
\hline ARTICLE INFO & ABSTRACT \\
\hline $\begin{array}{l}\text { Article History: } \\
\text { Received 08 February } 2019 \\
\text { Accepted } 04 \text { March } 2019 \\
\text { Available online } 1 \text { July } 2019\end{array}$ & $\begin{array}{l}\text { The studies related to new renewable energy are still } \\
\text { being developed. This study aims to design taperless } \\
\text { blades on wind turbines, case studies at PT. Lentera } \\
\text { Bumi Nusantara. The wind speed conditions in } \\
\text { Tasikmalaya which are considered relatively moderate }\end{array}$ \\
\hline $\begin{array}{l}\text { Keywords: } \\
\text { Chord } \\
\text { Twist angle } \\
\text { Blades } \\
\text { Taperless } \\
\text { Wind turbine }\end{array}$ & $\begin{array}{l}\text { characteristics in Tasikmalaya. Microsoft Excel, Qblade, } \\
\text { Solid Works, and aerodynamic equations have been } \\
\text { used to design a blade. The result shows that the blades } \\
\text { have a solid, easy to make and affordable structure that } \\
\text { can produce mechanical power at low wind speeds with } \\
\text { a radius, diameter hub and chord length of } 0.8 \mathrm{~m}, 0.19 \mathrm{~m} \\
\text { and } 0.12 \mathrm{~m} \text {, respectively. A twisting angle at the base } \\
\text { and at the end of the blade are } 11.14^{\circ} \text { and } 7.17^{\circ} \text {. } \\
\text { respectively. The conclusion of this design exhibited that } \\
\text { the blade design with the same edge blade can be } \\
\text { applied to moderate wind speeds to produce efficient, } \\
\text { compact and affordable wind turbines with wind } \\
\text { characteristics in Tasikmalaya, Indonesia. }\end{array}$ \\
\hline
\end{tabular}

Dinamika Teknik Mesin, Vol. 9, No. 2, Juli 2019, p. ISSN: 2088-088X, e. ISSN: 2502-1729

\section{PENDAHULUAN}

Indonesia merupakan salah satu negara dengan sumber daya alam berlimpah yang berpotensi menjadi energi terbarukan. Saat ini, perkembangan energi terbarukan bertenaga angin menjadi fokus penelitian dari para peneliti dan industriawan dikarenakan indonesia berada di daerah ekuador yang mendapatkan pergerakan udara lebih banyak (Zahra dan Situmorang, 2015). Ketergantungan terhadap bahan fossil fuels dapat dipecahkan dengan menggunakan energi bertenaga angin. Hasil mapping oleh Lembaga Penerbangan Antariksa Nasional Indonesia melaporkan bahwa kecepatan angin rata-rata di indonesia diatas $5 \mathrm{~m} / \mathrm{s}$ (Gibran dkk., 2015).

Beberapa studi telah merancang turbin angin dan tipe bilah yang disesuaikan dengan karakteristik pergerakan angin di perkotaan. Nishizawa (2011) telah merancang turbin angin untuk daerah perkotaan yang memiliki kecepatan angin berkisar 3-7 m/s. la melaporkan bahwa turbin angin yang cocok untuk daerah perkotaan adalah turbin angin mikro, hal ini dikarenakan tip speed ratio 
Dinamika Teknik Mesin. Sari dan Laksmana: Perancangan bilah tipe taperless pada kincir angin: studi kasus di PT. Lentera Bumi Nusantara Tasikmalaya

(TSR) yang dimiliki oleh jenis turbin ini kecil sehingga kebisingan dapat diminimalkan saat turbin angin berkerja. Kemudian, Hatta dan Martin (2017) telah mendesain bilah tipe inverse taper pada turbin angin sumbu horizontal. Mereka menemukan bahwa bilah inverse taper yang dirancang memiliki nilai coeffisien power $(C p)$ sebesar 0,5 dan cocok untuk kecepatan angin 3-7 m/s. Selain itu, mereka melaporkan bahwa bilah yang dirancang memiliki jari-jari, diameter hub, panjang chord awal dan ujung sebesar $1,1 \mathrm{~m}, 2 \mathrm{~m}, 0,13 \mathrm{~m}$ dan $0,27 \mathrm{~m}$, berturut-turut. Sudut puntir pangkal dan ujung telah diketahui sebesar $20,4^{\circ}$ dan $5,6^{\circ}$ berturut-turut, dan berat per bilah sekitar $0,7 \mathrm{~kg}$. Madi (2017) telah merancang bilah tipe tapper dimana jenis dari bilah ini mengecil ke ujung menggunakan NACA 4412 pada turbin angin sumbu horizontal. Hasil rancangannya menunjukkan bahwa bilah yang dirancang memiliki jari-jari $1 \mathrm{~m}$ dan panjang chord dan sudut puntir awal sebesar $0,15 \mathrm{~m}$ dan 10,66 ; sedangkan ujung bilah dan sudut puntir ujung sebesar $0,03 \mathrm{~m}$ dan $4,08^{\circ}$ berturut-turut. Nilai koefisien liftkoefesien drag $\left(\mathrm{Cl} / \mathrm{Cd}\right.$ ) ditemukan sebesar 133,5 dengan sudut $A / p h a 6^{\circ}$, dan pada tip speed ratio (TSR) sebesar 7. Demikian juga, Ismail dan Arrahman (2017) telah merancang bilah tipe pada turbin angin sumbu horizontal. Mereka melaporkan bahwa kecepatan angin yang digunakan untuk merancang sebesar $7,5 \mathrm{~m} / \mathrm{s}$ dengan ketinggian $110 \mathrm{~m}$, nilai tip speed ratio adalah 9 dengan radius rotor sebesar $85 \mathrm{~m}$ dan diameter hub sebesar $10 \mathrm{~m}$. Rotor telah diketahui sebesar 7,62 rpm. Mereka juga melaporkan bahwa pengujian rotor menggunakan software Q-Blade dengan sudut pitch 2,95 dan kecepatan awalan angin untuk memutar turbin (cut in) sebesar $3 \mathrm{~m} / \mathrm{s}$ dapat menghasilkan koefisien daya $(C p)$ adalah 0,493. Dari literatur-literatur diatas menunjukkan bahwa desain bilah taperless untuk turbin angin belum diselidiki. Dari berbagai tipe bilah yang tersedia, tipe bilah taperless adalah bilah yang paling mudah dalam pembuatannya, nilai efesiensi ideal dari bilah dapat mencapai $40 \%$ dan cocok untuk kondisi kecepatan angin 5-10 m/s (Hatta dan Martin, 2017).

Dalam pemilihan tipe bilah, faktor $C p$ dan TSR sangat penting untuk diperhatikan. Semakin besar nilai $C p$ menunjukkan kemampuan sebuah turbin untuk mendapatkan energi semakin tinggi. Demikian juga dengan nilai TSR; semakin besar nilai TSR maka akan semakin besar putarannya. Hal ini berarti bahwa kecepatan angin, tip speed ratio, koefisien lift dan drag merupakan parameter yang penting untuk diselidiki dari bilah jenis taperless ini karena dapat mempengaruhi performansi dari suatu turbin.

Oleh sebab itu, studi ini bermaksud untuk mendesain bilah jenis taperless pada kincir angin sumbu horizontal. Efisiensi dari bilah, kecepatan angin, tip speed ratio, koefisien lift dan drag telah dilaporkan. Penelitian ini diharapkan dapat memberikan informasi terkait jenis bilah taperless untuk turbin angin yang cocok untuk kondisi angin dengan kecepatan sedang $5-10 \mathrm{~m} / \mathrm{s}$.

\section{METODE PENELITIAN}

\subsection{Perancangan}

Tipe bilah taperless dari turbin angin sumbu horizontal (TASH) 3 bilah telah dirancang dalam studi ini. Persamaan aerodinamis telah digunakan untuk mendesain bilah, Qblade software dimaksudkan untuk menyelidiki performa dan karakteristik dari bilah, sedangkan microsoft excel; menentukan geometri bilah.

Dari hasil perhitungan daya rencana didapatkan bahwa jari-jari yang digunakan adalah $0,8 \mathrm{~m}$, dengan asumsi efesiensi bilah yang akan dirancang ialah dalam rentang 0,3-0,4 dengan kecepatan angin maksimal $12 \mathrm{~m} / \mathrm{s}$. Material yang digunakan adalah kayu mahoni; hal ini dikarenakan material kayu memiliki sifat kuat tapi ringan dan mudah didapatkan (Sari, 2018; Piggot, 2000). Tiap-tiap bilah kayu yang dirancang memiliki berat $1 \mathrm{~kg}$ per bilah, jenis airfoil yang digunakan adalah NACA 4415 dengan nilai $\mathrm{Cl} / \mathrm{Cd}$ sebesar 129,5 (Hasting dkk, 1984).

\subsection{Validasi rancangan}

Validasi telah dilakukan terhadap hasil rancangan menggunakan Qblade software; hal ini dimaksudkan untuk mengetahui karakteristik turbin angin yang telah dirancang yang disajikan dalam bentuk grafik dan kerja optimal dari turbin dibawah kondisi yang diterapkan.

\section{HASIL DAN PEMBAHASAN}

Hasil pengukuran dimensi bilah dilakukan dengan menetapkan variabel-variabel seperti disajikan dalam tabel 1. Output dari turbin angin yang akan dihasilkan menjadi dasar dilakukannya pengukuran ini.

Geometri bilah telah dihasilkan dengan menggunakan persamaan aerodinamis dan jumlah elemen bilah telah diketahui sebanyak 11 elemen. 
Dinamika Teknik Mesin. Sari dan Laksmana: Perancangan bilah tipe taperless pada kincir angin: studi kasus di PT. Lentera Bumi Nusantara Tasikmalaya

Tabel 1 Variabel-variabel dari geometri bilah taperless

\begin{tabular}{ll}
\hline Daya rencana & $500 \mathrm{~W}$ \\
Efesiensi bilah rencana & $0,3-0,4$ \\
Efesiensi generator & 0,9 \\
Efesiensi transmisi & 0,9 \\
Densitas Udara & $1,225 \mathrm{~kg} / \mathrm{m}^{3}$ \\
Torsi & $8,5 \mathrm{Nm}$ \\
Efesiensi $(C p)$ & 0,42 \\
Tip Speed Ratio & 7 \\
Kecepatan angin rancangan & $12 \mathrm{~m} / \mathrm{s}$ \\
\hline
\end{tabular}

Penentuan nilai panjang chord serta sudut puntir dari setiap elemen dapat ditentukan jika TSR parsial dari masing-masing elemen telah diketahui.

Nilai TSR dapat ditentukan dengan persamaan 1 (Burton, 2001):

$\lambda r=\frac{r}{R} \lambda R$

dengan, $\lambda r$ adalah TSR parsial, $r$ adalah jari-jari parsial, $R$ adalah jari-jari yang digunakan dan $\lambda R$ adalah $T S R$ yang digunakan dalam rancangan.

Sebelum dilakukan perhitungan sudut puntir dari elemen bilah, perhitungan flow angle pada setiap elemen bilah telah ditentukan menggunakan persamaan 2 (Burton, 2001):

$\phi=2 / 3 \tan ^{-1}(1 / \lambda r)$

dengan, $\phi$ adalah flow angle (sudut alir); dan $\lambda r$ adalah TSR parsial. Selanjutnya, sudut puntir pada setiap elemen dihitung dengan persamaan 3 (Burton, 2001):

$\beta=\phi-\alpha$

dengan $\beta$ adalah sudut puntir, $\phi$ adalah flow angle (sudut alir) dan $\alpha$ adalah sudut serang fluida. Pengukuran panjang chord $(\mathrm{Cr})$ dari setiap elemen bilah dapat diperoleh dengan persamaan 4 (Burton, 2001):

$C r=\frac{16 \pi R(R / r)}{9 \lambda^{2} B C r}$

dengan $\mathrm{Cr}$ adalah panjang chord, $\mathrm{R}$ adalah jari-jari yang digunakan, $\mathrm{r}$ adalah jari-jari parsial, $\lambda R$ adalah $T S R$ yang digunakan, B adalah jumlah bilah dan $\mathrm{Cl}$ adalah nilai koefisien lift.

Teknik linierisasi $75 \%$ dari elemen bilah telah dilakukan; hal ini dimaksudkan untuk mempermudah proses optimasi. Linierisasi telah dilakukan dengan menggunakan bantuan microsoft excel, seperti ditunjukkan oleh persamaan 5 (Gibran dkk. 2015). Hasil linierisasi dapat dilihat pada Tabel 2.

$y=-6,3053 x+12,216$

dengan $y$ adalah optimum twist dan $x$ menyatakan jari-jari parsial. Lebih lanjut, perangkat lunak solid works digunakan untuk membentuk geometri bilah dalam dua dimensi. Hasil dari pemodelan yang dihasilkan disajikan dalam gambar 1.

Selanjutnya, proses validasi; dalam proses ini hasil perhitungan geometri dimasukkan ke dalam Qblade. Hasil dari validasi ini diperlihatkan dalam gambar 2, 3 dan 4 yang meliputi daya, torsi, kecepatan putaran rotor, dan kecepatan angin, serta efisiensi dari bilah yang telah dihasilkan.

Bilah rancangan dengan jari-jari bilah $0,8 \mathrm{~m}$, panjang bilah $0,77 \mathrm{~m}$, lebar bilah atau chord 0,12 m dan tebal bilah 0,018 m telah dihasilkan dalam studi ini. Dari hasil simulasi Qblade (lihat gambar 2) memperlihatkan bahwa pada kecepatan angin $3 \mathrm{~m} / \mathrm{s}$, bilah mulai cut in atau menghasilkan energi listrik. Kecepatan angin rancangan, nilai TSR dan torsi mekanik telah diperoleh sebesar $12 \mathrm{~m} / \mathrm{s}, 7$ 
dan $8,5 \mathrm{Nm}$ berturut-turut (lihat gambar 2). Lebih lanjut, nilai efesiensi $(C p)$ telah ditemukan sebesar 0,42 (lihat gambar 3 ) dan daya mekanik yang dihasilkan sebesar 500 watt pada kecepatan putaran rotor sebesar $300 \mathrm{rpm}$ (lihat gambar 4). Wood, (2011) menyatakan bahwa sistem furling dapat membantu mencegah rotor overspeeding dan turbin angin berhenti menghasilkan daya listrik (pada 13 $\mathrm{m} / \mathrm{s})$.

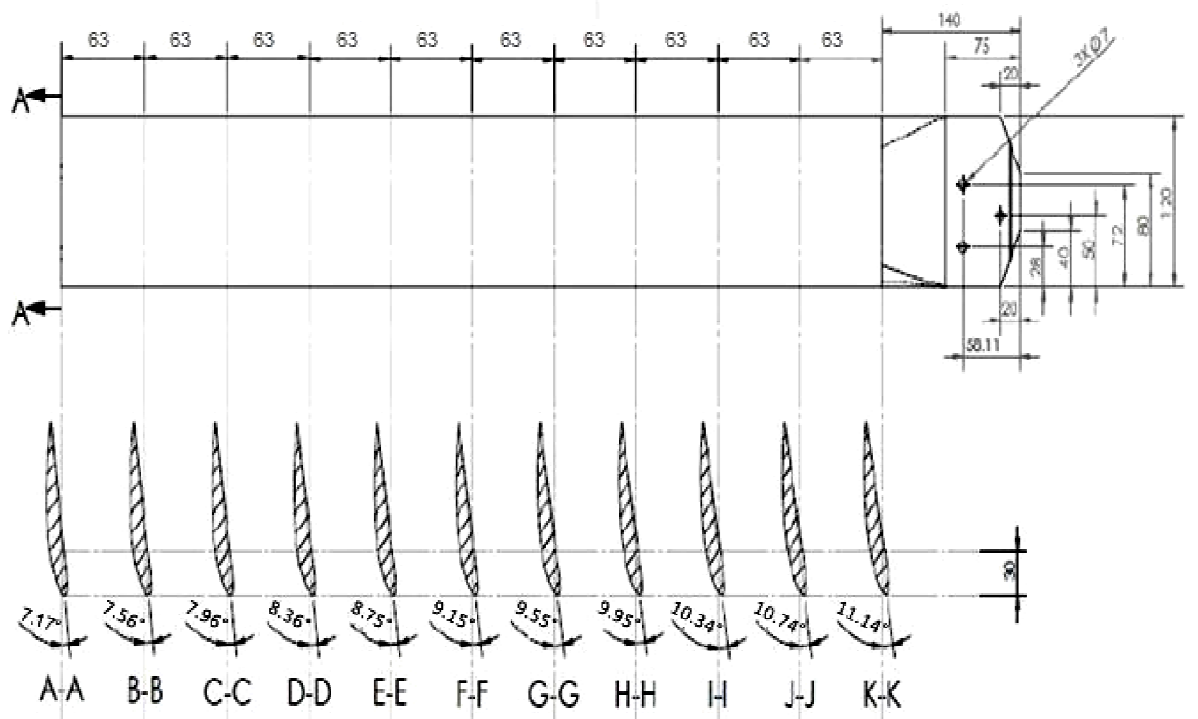

Gambar 1. Geometri bilah jenis taperless dalam 2 dimensi. A-A, B-B, C-C, D-D; E-E, F-F, G-G, H-H, II, J-J, dan K-K merupakan section penampang pada elemen 0 , 1, 2, 3, 4, 5, 6, 7, 8, 9, dan 10 dari bilah taperless.

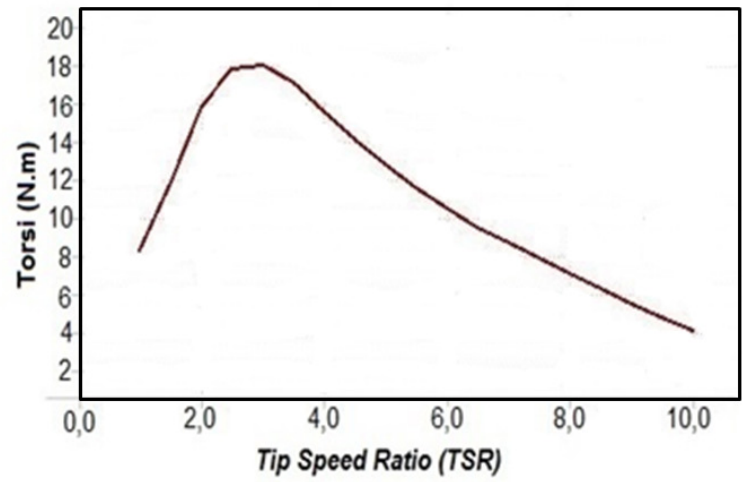

Gambar 2. Hubungan torsi dengan tip speed ratio dari bilah jenis taperless

Tabel 2. Geometri bilah taperless

\begin{tabular}{ccc}
\hline Elemen & $\begin{array}{c}\text { Jari-jari parsial } \\
(\mathrm{m})\end{array}$ & $\begin{array}{c}\text { Optimum twist } \\
\left({ }^{\circ}\right)\end{array}$ \\
\hline 0 & 0,17 & 11,14 \\
1 & 0,23 & 10,74 \\
2 & 0,30 & 10,34 \\
3 & 0,36 & 9,95 \\
4 & 0,42 & 9,55
\end{tabular}


Dinamika Teknik Mesin. Sari dan Laksmana: Perancangan bilah tipe taperless pada kincir angin: studi kasus di PT. Lentera Bumi Nusantara Tasikmalaya

\begin{tabular}{ccc}
5 & 0,49 & 9,15 \\
6 & 0,55 & 8,75 \\
7 & 0,61 & 8,36 \\
8 & 0,67 & 7,96 \\
9 & 0,74 & 7,56 \\
10 & 0,80 & 7,17 \\
\hline
\end{tabular}

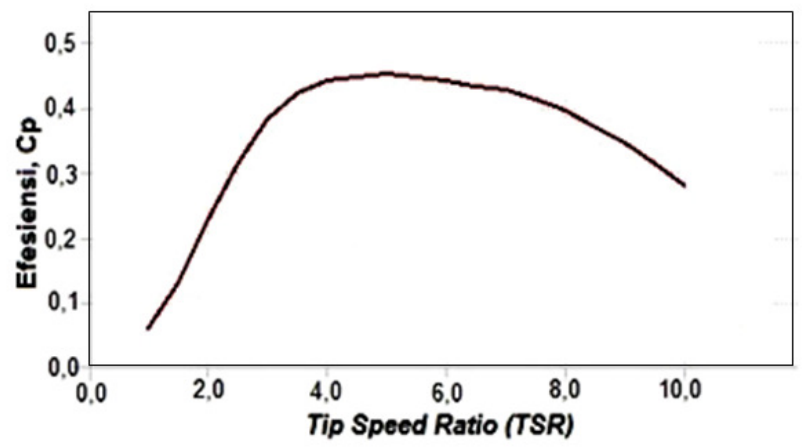

Gambar 2. Hubungan efesiensi dengan tip speed ratio dari bilah jenis taperless.

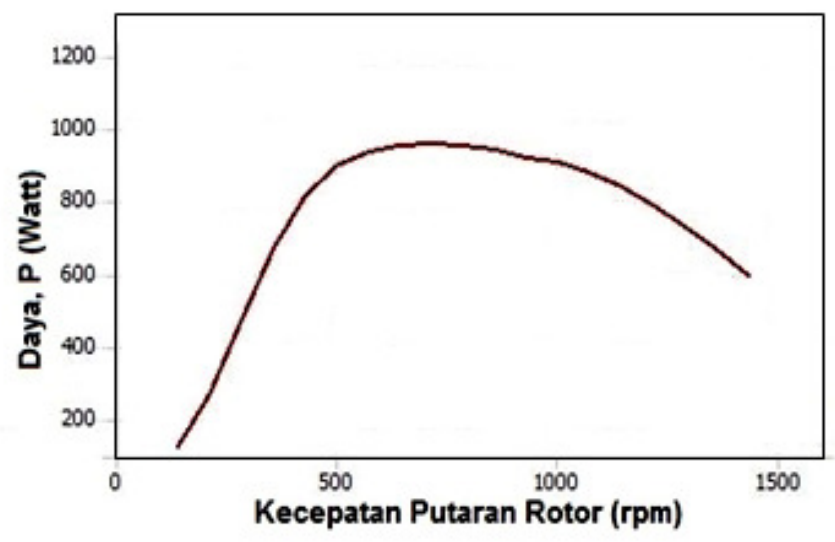

Gambar 4. Hubungan daya dengan kecepatan putaran rotor dari bilah jenis taperless.

\section{KESIMPULAN}

Desain bilah taperless telah dihasilkan. Hasil studi menunjukkan bahwa bilah yang yang dihasilkan memiliki jari-jari bilah 0,8 $\mathrm{m}$, panjang bilah $0,77 \mathrm{~m}$, lebar bilah (chord) $0,12 \mathrm{~m}$ dan tebal bilah $0,018 \mathrm{~m}$. Sudut puntir dari pangkal keujung sekitar $11,4^{\circ}$ sampai $7,17^{\circ}$. Hasil ini memperlihatkan bahwa penerapan bilah taperless pada turbin angin sesuai untuk kecepatan angin yang ada di Tasikmalaya dalam kisaran 7-12 m/s dengan nilai $C p$ maksimum 0,5. Material bilah taperless ini disarankan adalah kayu mahoni; dikarenakan ringan, kuat dan mudah dibandingkan dengan besi dan plastik. Desain bilah taperless ini diharapkan dapat menjadi alternatif bilah pada turbin angin untuk angin yang berkecepatan sedang.

\section{UCAPAN TERIMAKASIH}

Penulis mengucapkan terimakasih kepada semua pihak yang telah membantu baik berupa materi maupun pikiran sehingga penelitian sehingga paper ini terselesaikan. Yang kedua penulis mengucapkan terimakasih kepada Muhammad Al Roshady Said, ST selaku pembimbing lapangan 
Dinamika Teknik Mesin. Sari dan Laksmana: Perancangan bilah tipe taperless pada kincir angin: studi kasus di PT. Lentera Bumi Nusantara Tasikmalaya

pada penelitian dalam rangka praktik kerja lapangan ini yang bertempat di Tasikmalaya, Jawa Barat, Indonesia.

\section{DAFTAR PUSTAKA}

Burton T., 2001, Wind energy handbook, John Wiley \& Sons, Ltd, England.

Fried L., 2015, Global wind statistic 2014, Belgium, Brussels.

Gibran F., Safhire., 2015, Simulation of inverse taper wind turbine blade and transmission for indonesia wind condition, Indonesian Scholars International Convention, London.

Hatta M., Martin A., 2017, Perancangan bilah tipe inverse taper pada turbin angin berdasarkan kondisi angin di pekanbaru, jurnal Jom FTEKNIK, 4(1), 1-4.

Hasting R.C., 1984, Studies of the flow field near a NACA 4412 aerofoil at nearly maximum lift, Royal Aircraft Establishment, Farnborough, England.

Ismail, Arrahman T., 2017, Perancangan turbin angin sumbu horizontal tiga sudu dengan kapasitas 3 MW, Jurnal /PRESISI, 18(2), 10-19.

Madi, 2017, Studi perancangan horizontal axis wind turbine dengan perbedaan desain air foil pada bilah jenis taper untuk pembangkit listrik tenaga angin laut di Pantai Ciheras, PT. Lentera Angin Nusantara Surabaya, Tugas Akhir, Institut Teknologi Sepuluh Nopember Surabaya.

Nishizawa Y., 2011, An experimental study of the shape of rotor for horizontal-axis wind turbine, Japan, InTech.

Piggot H., 2000, Windpower workshop building your own wind turbine, British Wind Energy Association, Peninsula.

Sari N.H., 2018, Material teknik, Edisi pertama, Deepublish, Yogyakarta.

Wood D., 2011, Small wind turbines, Springer, Canada.

Zahra I.N., 2014, Pengenalan teknologi pemanfaatan energi angin Tasikmalaya, PT. Lentera Bumi Nusantara, Tasikmalaya.

Zahra I.N., Situmorang., 2015, Renewable energi nusantara Tasikmalaya, PT. Lentera Bumi Nusantara, Tasikmalaya. 